DOI: https://doi.org/10.46296/yc.v4i7edesp.0063

\title{
CÓDIGO DE ÉTICA DE LOS PAÍSES LATINOAMERICANOS
}

\section{CODE OF ETHICS OF LATIN AMERICAN COUNTRIES}

\author{
Caicedo-Guale Liliana Carolina ${ }^{\text {** }}$ Vera-García Maritza²; Sornoza-Palma Williams \\ Kevin ${ }^{3}$ \\ ${ }^{1}$ Docente de la Universidad Laica Eloy Alfaro de Manabí, ULEAM. Manta, Ecuador. \\ ${ }^{2}$ Docente de la Universidad Técnica de Manabí, UTM. Portoviejo, Ecuador. \\ ${ }^{3}$ Universidad Técnica de Manabí, UTM. Portoviejo, Ecuador.
}

*Correo: liliana.caicedo@uleam.edu.ec

\begin{abstract}
Resumen
La práctica de la psicología, bien sea como disciplina científica o como servicio público, está basada en dos fundamentos principales: el primero está compuesto por un conjunto de conocimientos y habilidades que se han ido adquiriendo a través de la investigación y la práctica psicológica; el segundo se compone de la ética aplicada en el desarrollo de ese conjunto de conocimientos y habilidades, y de las acciones llevadas a cabo cuando estas se aplican para responder a las demandas de prestación de servicios a los usuarios. (Consejo General de Colegios de Psicologos de España, 2009). Los deberes y derechos de la profesión del psicólogo no sólo se construyen a partir de la independencia y autonomía profesional, además, están regidos por principios deontológicos que son: respeto a los derechos humanos y dignidad de las personas, compromiso profesional científico, competencia, responsabilidad social e integridad, los cuales están orientados al establecimiento de reglas sobre la conducta profesional, frente a situaciones concretas. (Colegios de Psicologos de la Provincvia de Chubut, 2001). Se hace énfasis en diversos ámbitos como su imagen, las penalizaciones, la intervención profesional desde diferentes facetas, tales como: investigación, educación, promoción, prevención y atención psicológica. Esto refleja la diversidad de criterios en cuanto al accionar del psicólogo en cada país y su postura frente a dilemas éticos.
\end{abstract}

Palabras clave: Psicología, ética, derechos, Latinoamérica.

\begin{abstract}
The practice of psychology, either as a scientific discipline or as a public service, is based on two main foundations: the first is composed of a set of knowledge and skills that have been acquired through psychological research and practice; the second is made up of the ethics applied in the development of that set of knowledge and skills, and the actions carried out when these are applied to respond to the demands for the provision of services to users. (General Council of Colleges of Psychologists of Spain, 2009). The duties and rights of the psychologist profession are not only built from professional independence and autonomy, but they are also governed by deontological principles that are: respect for human rights and dignity of people, scientific professional commitment, competence, responsibility social and integrity, which are oriented to the establishment of rules on professional conduct, in the face of specific situations. (Colleges of Psychologists of the Province of Chubut, 2001). Emphasis is placed on various areas such as their image, penalties, professional intervention from different facets, such as: research, education, promotion, prevention, and psychological care. This reflects the diversity of criteria regarding the actions of the psychologist in each country and their position in the face of ethical dilemmas.
\end{abstract}

Keywords: Psychology, ethics, rights, Latin America.

Información del manuscrito:

Fecha de recepción: 14 de septiembre de 2020.

Fecha de aceptación: 12 de noviembre de 2020.

Fecha de publicación: 16 de noviembre de 2020. 


\section{Introducción}

Existen diversos códigos éticos de sociedades psicológicas a nivel mundial, el más influyente es el propuesto por la Asociación Psicológica Americana (APA) cuyos principios han sido utilizados tanto por la Federación Europea de Asociaciones de Psicólogos (EFPA) para la creación de su código ético, como por los colegios de psicólogos en América Latina.

En Europa, frente a la variedad de códigos propuestos por cada país, en 1990 la EFPA estableció un metacódigo para todos los psicólogos en Europa, teniendo en cuenta la libertad de ejercicio de los profesionales dentro de la Unión Europea. Uno de los propósitos de esta federación fue evitar que un psicólogo sancionado en un país pudiera ejercer en otro. El caso de Estados Unidos y Canadá, donde los Consejos Estatales de las Asociaciones de Psicólogos se comunican entre ellos, se tomó como modelo para la elaboración de este. (Consejo General de Colegios de Psicologos de España, 2009)

En Latinoamérica cada país ha ido instaurando su propio código, es así, que por su parte la sociedad Mexicana de Psicólogos (SMP) creó su primer código ético en 1984, basado en las normativas propuestas por la APA. En 1999 presentó la segunda edición del código cuyo objetivo era establecer un código que rigiera a los profesionales en Norteamérica. La última edición se presentó en el 2007, en el cual remarca que el desconocimiento del mismo no justifica ninguna falta ética. (Sociedad Mexicana de Psicología, 2007).

En Centroamérica y el Caribe, los países que han establecido su código ético son: Guatemala, Hondura, Panamá, Cuba, República dominicana y Puerto Rico, los cuales han sido creados por colegios y asociaciones de psicólogos que rigen a cada país.

En Sudamérica; Argentina, Brasil, Paraguay y Uruguay participaron en la creación del Mercado Común del Sur (Mercosur) en 1991 y posteriormente se asociaron Chile y Bolivia. Esta organización constituyó un hecho institucional de gran relevancia, no sólo desde un punto de vista político-económico, sino que abarcó una gran diversidad de 
temáticas concernientes a los intereses comunes de los países miembros, como la elaboración de normativas que rigen el accionar de los profesionales y psicólogos en formación. Se estableció la importancia de generar un currículum general para la formación básica común en todos los países de la región, con determinados contenidos mínimos, que a su vez garantizara el pluralismo teórico y metodológico de la formación científico-profesional, así como la formación generalista. (Ferrero \& Andrade, 2007)

Por su parte, Perú recientemente ha publicado las normativas para el accionar del psicólogo, las mismas que han estado en constante observación desde 1993 y finalmente en el 2018 se presentaron de manera oficial. (Colegio de Psicólogos del Perú, 2018)

En este estudio se ha realizado una revisión bibliográfica de los códigos éticos en los siguientes países: México, Argentina, Colombia, Cuba, Panamá y Venezuela, se ha evidenciado que todas las asociaciones y colegios han creado sus normativas en base a los principios deontológicos antes mencionados. (Ver tabla 1).

\section{Objetivo}

Comparar los códigos éticos en los países de Latinoamérica para establecer semejanzas y diferencias estructurales y éticas.

\section{Metodología}

El presente estudio se realizó mediante una investigación cualitativa a nivel exploratoria de diseño documental, en la cual se realizó el análisis de los códigos éticos de los países latinoamericanos, seleccionados por la viabilidad de información bibliográfica y conveniencia a esta investigación.

\section{Resultados}

Tabla 1. Principios Deontológicos.

\begin{tabular}{|l|c|c|c|c|c|c|}
\hline & VENEZUELA & MÉXICO & CUBA & PANAMÁ & COLOMBIA & ARGENTINA \\
\hline Justicia & $\checkmark$ & $\checkmark$ & $\checkmark$ & $\checkmark$ & $\checkmark$ & $\checkmark$ \\
\hline
\end{tabular}




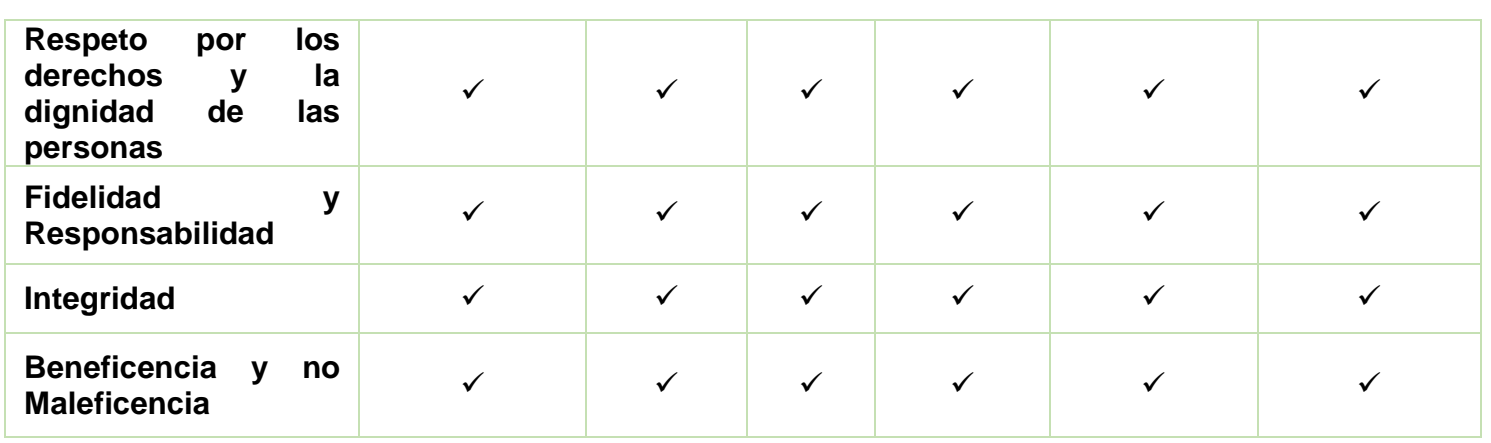

Fuente: Revisión documental. Elaborado por: Grupo de investigadores.

Tabla 2. Apartados de los códigos por países.

\begin{tabular}{|c|c|c|c|c|c|c|}
\hline & Venezuela & México & Cuba & Panamá & Colombia & Argentina \\
\hline $\begin{array}{c}\text { Resolución de } \\
\text { cuestiones éticas }\end{array}$ & $\begin{array}{l}\text { Deberes éticos } \\
\text { frente a las } \\
\text { autoridades. } \\
\text { Deberes éticos } \\
\text { en el ejercicio } \\
\text { institucional de } \\
\text { la Psicología. } \\
\text { Sanciones y } \\
\text { las causales } \\
\text { que las } \\
\text { determinan. }\end{array}$ & $\begin{array}{l}\text { Ejercicio } \\
\text { libre de la } \\
\text { profesión. }\end{array}$ & $\begin{array}{l}\text { De carácter } \\
\text { general. } \\
\text { Fines } \\
\text { profesionales. } \\
\text { Actuación } \\
\text { profesional. } \\
\text { Comportamien } \\
\text { to profesional. } \\
\text { Contravencion } \\
\text { es al código y } \\
\text { sanciones. }\end{array}$ & $\begin{array}{l}\text { Actuación del (la) } \\
\text { psicólogo(a) como } \\
\text { auxiliar de la } \\
\text { justicia. } \\
\text { Procedimiento } \\
\text { para la sanción. } \\
\text { Faltas a la ética en } \\
\text { que incurran los } \\
\text { (las) } \\
\text { psicólogos(as). }\end{array}$ & $\begin{array}{l}\text { Disposiciones } \\
\text { generales. } \\
\text { Integridad. } \\
\text { Evitación de daño. } \\
\text { Interferencias en la } \\
\text { actividad profesional. } \\
\text { Delegación } \\
\text { supervisión. } \\
\text { Aplicaciones y } \\
\text { contexto social. y } \\
\text { Relaciones con la } \\
\text { sociedad y con el } \\
\text { Estado. } \\
\text { Régimen disciplinario. }\end{array}$ & $\begin{array}{l}\text { Responsabilidad } \\
\text { en las relaciones } \\
\text { profesionales. }\end{array}$ \\
\hline Competencias & & $\begin{array}{l}\text { Ejercicio } \\
\text { libre de la } \\
\text { profesión. }\end{array}$ & $\begin{array}{l}\text { De carácter } \\
\text { general } \\
\text { Desarrollo } \\
\text { profesional } \\
\text { Profesión del } \\
\text { psicólogo. } \\
\text { Competencias } \\
\text { profesionales }\end{array}$ & $\begin{array}{l}\text { Derechos, deberes } \\
\text { y prohibiciones del } \\
\text { psicólogo (a) en el } \\
\text { ejercicio de la } \\
\text { profesión } \\
\text { De la actuación del } \\
\text { (la) psicólogo(a) } \\
\text { como auxiliar de la } \\
\text { justicia }\end{array}$ & $\begin{array}{l}\text { Competencias } \\
\text { profesionales. } \\
\text { Integridad. } \\
\text { Responsabilidad } \\
\text { científica y profesional. } \\
\text { Evitación de daño. } \\
\text { Delegación } \\
\text { supervisión. } \\
\text { Aplicaciones } \\
\text { contexto social. y }\end{array}$ & \\
\hline $\begin{array}{l}\text { Relaciones } \\
\text { humanas }\end{array}$ & $\begin{array}{l}\text { Deberes del } \\
\text { psicólogo } \\
\text { respecto a sus } \\
\text { colegas }\end{array}$ & $\begin{array}{l}\text { Relaciones } \\
\text { entre } \\
\text { colegas. }\end{array}$ & & $\begin{array}{l}\text { De la relación } \\
\text { entre los } \\
\text { profesionales de la } \\
\text { psicología }\end{array}$ & $\begin{array}{l}\text { Responsabilidad } \\
\text { social. } \\
\text { Respeto por los otros. } \\
\text { Evitación de daño. } \\
\text { Delegación } \\
\text { supervisión. } \\
\text { Relaciones y } \\
\text { colegas y otros } \\
\text { profesionales. }\end{array}$ & $\begin{array}{l}\text { Responsabilidad } \\
\text { con los colegas. } \\
\text { Responsabilidad } \\
\text { con la profesión } \\
\text { y la comunidad. }\end{array}$ \\
\hline $\begin{array}{c}\text { Privacidad y } \\
\text { confidencialidad }\end{array}$ & $\begin{array}{l}\text { Deberes del } \\
\text { psicólogo para } \\
\text { con el } \\
\text { consultante } \\
\text { Secreto } \\
\text { profesional }\end{array}$ & $\begin{array}{l}\text { Ejercicio } \\
\text { libre de la } \\
\text { profesión. }\end{array}$ & $\begin{array}{l}\text { Secreto } \\
\text { profesional } \\
\text { Respeto a } \\
\text { persona y a la } \\
\text { diversidad } \\
\text { social. } \\
\text { Actuación } \\
\text { profesional }\end{array}$ & $\begin{array}{l}\text { Consentimiento } \\
\text { informado. } \\
\text { Secreto } \\
\text { profesional y } \\
\text { límites. }\end{array}$ & $\begin{array}{l}\text { Integridad. } \\
\text { Secreto profesional. } \\
\text { Evitación de daño. } \\
\text { Guardar secreto } \\
\text { profesional. }\end{array}$ & $\begin{array}{l}\text { Consentimiento } \\
\text { informado. } \\
\text { Secreto } \\
\text { profesional } \\
\text { Límites del } \\
\text { secreto } \\
\text { profesional. }\end{array}$ \\
\hline $\begin{array}{l}\text { Publicidad y } \\
\text { otras } \\
\text { declaraciones } \\
\text { publicas }\end{array}$ & & $\begin{array}{l}\text { Ejercicio } \\
\text { libre de la } \\
\text { profesión. }\end{array}$ & $\begin{array}{l}\text { Respeto a } \\
\text { persona y a la } \\
\text { diversidad } \\
\text { social }\end{array}$ & $\begin{array}{l}\text { De los (las) } \\
\text { psicólogos(as) y la } \\
\text { publicidad. }\end{array}$ & $\begin{array}{l}\text { Evitación de daño. } \\
\text { Presentación y } \\
\text { promoción profesional. }\end{array}$ & $\begin{array}{l}\text { Declaraciones } \\
\text { públicas. } \\
\text { Publicidad y } \\
\text { divulgación. }\end{array}$ \\
\hline $\begin{array}{l}\text { Registros y } \\
\text { honorarios }\end{array}$ & $\begin{array}{l}\text { Honorarios } \\
\text { profesionales }\end{array}$ & $\begin{array}{l}\text { Ejercicio } \\
\text { libre de la } \\
\text { profesión. }\end{array}$ & & & $\begin{array}{l}\text { Honorarios y acuerdos } \\
\text { financieros. }\end{array}$ & \\
\hline $\begin{array}{l}\text { Educación y } \\
\text { capacitación }\end{array}$ & $\begin{array}{l}\text { Deberes éticos } \\
\text { en el área de la } \\
\text { docencia }\end{array}$ & Docencia. & $\begin{array}{l}\text { Responsabilid } \\
\text { ades } \\
\text { docentes. }\end{array}$ & & Evitación de daño. & Docencia. \\
\hline
\end{tabular}




\begin{tabular}{|c|c|c|c|c|c|c|}
\hline & & & \multirow[b]{2}{*}{$\begin{array}{l}\text { Investigación } \\
\text { psicológica } \\
\text { Prevenciones } \\
\text { del } \\
\text { investigador } \\
\text { con seres } \\
\text { humanos y } \\
\text { animales. la } \\
\text { De los } \\
\text { comunicación } \\
\text { de resultados } \\
\text { investigativos }\end{array}$} & \multirow{3}{*}{$\begin{array}{l}\text { De la participación } \\
\text { de los (las) } \\
\text { psicólogos(as) en } \\
\text { las investigaciones } \\
\text { científicas. }\end{array}$} & \multirow[b]{2}{*}{$\begin{array}{l}\text { Responsabilidad } \\
\text { científica y profesional. } \\
\text { Evitación de daño. } \\
\text { Investigación } \\
\text { científica. }\end{array}$} & \multirow[b]{2}{*}{$\begin{array}{l}\text { Investigación. } \\
\text { Publicaciones. }\end{array}$} \\
\hline $\begin{array}{c}\text { Investigación y } \\
\text { publicación }\end{array}$ & $\begin{array}{l}\text { Deberes éticos } \\
\text { en el área de } \\
\text { investigación }\end{array}$ & $\begin{array}{l}\text { Investigació } \\
\mathrm{n} \text {. }\end{array}$ & & & & \\
\hline Evaluación & $\begin{array}{l}\text { Deberes éticos } \\
\text { relativos a } \\
\text { recursos e } \\
\text { instrumentos } \\
\text { de trabajo } \\
\text { psicológico. }\end{array}$ & $\begin{array}{l}\text { Pruebas e } \\
\text { instrumentos } \\
\text { de } \\
\text { evaluación. }\end{array}$ & $\begin{array}{l}\text { De los } \\
\text { procedimiento } \\
\text { s, métodos y } \\
\text { técnicas de la } \\
\text { psicología. }\end{array}$ & & $\begin{array}{l}\text { Evitación de daño } \\
\text { Evaluación } \\
\text { diagnóstico }\end{array}$ & \\
\hline Terapia & & $\begin{array}{l}\text { Ejercicio } \\
\text { libre de la } \\
\text { profesión. }\end{array}$ & $\begin{array}{l}\text { De los } \\
\text { procedimiento } \\
\text { s, métodos y } \\
\text { técnicas de la } \\
\text { psicología. }\end{array}$ & $\begin{array}{l}\text { Derechos, deberes } \\
\text { y prohibiciones del } \\
\text { psicólogo (a) en el } \\
\text { ejercicio de la } \\
\text { profesión. } \\
\text { Del conflicto de } \\
\text { intereses entre el } \\
\text { (la) psicólogo(a) y } \\
\text { el (la) cliente o } \\
\text { paciente. }\end{array}$ & $\begin{array}{l}\text { Integridad } \\
\text { Responsabilidad } \\
\text { científica y profesional } \\
\text { Evitación de daño } \\
\text { Relación terapéutica. }\end{array}$ & $\begin{array}{l}\text { Consentimiento } \\
\text { informado } \\
\text { Responsabilidad }\end{array}$ \\
\hline Otros & $\begin{array}{l}\text { Deberes para } \\
\text { con el gremio. }\end{array}$ & & $\begin{array}{l}\text { Disposiciones } \\
\text { finales. }\end{array}$ & & & \\
\hline
\end{tabular}

Fuente: Revisión documental.

Elaborado por: Grupo de investigadores.

En la tabla No. 1 se especifica que los países analizados han establecido sus códigos éticos en los cinco principios deontológicos al igual que la APA y las otras organizaciones de psicólogos, tanto en Latinoamérica como en Europa.

En la tabla No. 2 se observa que los países estudiados en su mayoría incluyen 11 apartados en los cuales se especifican las normativas con relación a cada uno: resolución de cuestiones éticas, competencias, relaciones humanas, privacidad, confidencialidad, publicidad, registros, honorarios, educación, capacitación, investigación, publicación, evaluación, terapia, y otros con relación al gremio o a la asociación de cada país.

Los cinco países coinciden en el apartado de privacidad y confidencialidad, hacen énfasis en las excepciones con relación al secreto profesional; el límite de esta normativa seria en casos de menores de edad o personas incapacitadas para tomar decisiones, y se requiera la información en pro del bienestar del paciente, en caso de que se pueda evitar un delito y en caso de que el paciente dé su consentimiento por escrito. 
El código ético de Venezuela en su generalidad explica las obligaciones y deberes éticos del profesional con relación así mismo, sus colegas y la comunidad. El código consta de 11 capítulos que son: deberes éticos en la investigación, docencia, recursos e instrumentos de evaluación, ejercicio institucional, secreto profesional, honorarios, entre colegas, con el gremio, sanciones, disposiciones finales en las que refiere que todos los psicólogos del país se deben regir por dicho código, siendo la autoridad la federación, y por ultimo deberes para con los consultantes; en este último involucra normativas que tienen relación con la intervención y psicoterapia, aunque no lo específica de esta manera como los otros países.

Los códigos de México incluyen todos los apartados en su código ético. En México, los psicólogos poseen la libertad completa del ejercicio de la profesión, en comparación con otros países ya que tienen sus respectivas variaciones. Con base en estos principios, establece las normas a las que deben ajustarse la prestación de servicios, la investigación, la docencia, el uso de pruebas y métodos de registro, medición y evaluación, las relaciones entre colegas $\mathrm{y}$, en general, cualquier actividad propia de la profesión.

El código de Cuba consta de 20 artículos que especifican seis aparatados los cuales son: generalidades (artículos del 1 al 7, en relación al respeto a las personas, diversidad y responsabilidad profesional) Competencias del profesional (artículo 8), Investigación psicológica (artículos del 9 al 13) Docencia (artículo 14) Evaluación psicológica (artículo competencias profesionales (artículo 16 al 18) y contravenciones al código y sanciones (artículo 19 y 20) no especifica el apartado honorarios. En las disposiciones finales especifica la vigencia del código.

Panamá ha creado 26 artículos que especifican nueve capítulos: capitulo primero (especifica principios deontológicos), capitulo 2 (relación psicólogo - paciente; artículos del 1 al 6), capitulo 3 (conflicto de interés psicólogo - paciente; artículo 7), capitulo 4 (actuación del psicólogo como auxiliar de justicia; artículo del 8 al 11), capitulo 5 (investigación; articulo 12) capitulo 6 (relación entre 
profesionales; artículo del 13 al 17) capitulo 7 (publicidad: artículo del 18 al 20) capitulo 8 (sanciones: artículos del 21 al 24), capitulo 9 que especifica disposiciones finales en los artículos 25 y 26 en los que refiere que el código deroga los anteriores y a futuro será sometido a modificaciones de acuerdo a las innovaciones y acuerdos que se presenten. No detalla honorarios.

En las generalidades e introducción del código de Colombia refiere sobre los principios deontológicos. Está compuesto por 20 capítulos que especifican: fundamentos, disposiciones generales, competencias profesionales, integridad, responsabilidad científica y social, respeto por los otros, secreto profesional, evitación del daño, interferencias en la actividad profesional, delegación y supervisión, honorarios, promoción profesional, relación terapéutica, evaluación y diagnóstico, investigación científica, contexto social, relación entre colegas, relación con la sociedad y estado, y sanciones. Prohíbe la atención psicoterapéutica por medios tecnológicos.
Argentina toma como base los principios generales, acordados por los países miembros y asociados a la Mercosur, los cuales los registra en la introducción del código ético; el cual está compuesto por seis apartados en los cuales especifica: consentimiento informado, secreto profesional, responsabilidad en las relaciones (destinatarios, colegas y comunidad), investigación, docencia y declaraciones públicas (publicidad, divulgación y publicaciones). Específica, también que, en situaciones de catástrofe, urgencia o situaciones de riesgo, se podrá intervenir sin el consentimiento del consultante. En Ecuador, de manera descentralizada, cada colegio de profesionales propone su código de ética, lo que conlleva a que los psicólogos no se rijan bajo un mismo instrumento deontológico, evidenciando la diversidad de criterios y culturas propias de este país.

\section{Conclusiones}

El Código Ético se entiende como un instrumento para garantizar la protección de los usuarios de los servicios psicológicos, y para ofrecer al psicólogo un apoyo, tanto en la 
toma de decisiones, como en los casos en los que se enfrente a dilemas éticos. Es por ello por lo que la permanente evaluación y retroinformación de su aplicación, además del conocimiento de casos concretos de conflictos de naturaleza ética, servirán para mejorarlo y modificarlo continuamente, siempre con la finalidad de aumentar su eficacia

Los países latinoamericanos analizados, en comparación con los países europeos, los cuales cuentan con una organización que los ampara, desde un código ético común, estos no cuentan con uno en general, sino que, cada código se adapta al contexto local y en el mejor de los casos, regional.

A nivel nacional, en la actualidad, los psicólogos proceden sin un sustento legal y ético consensuado que respalde su accionar profesional; sin embargo, a nivel de algunas provincias se establecen instrumentos éticos que justifican la actuación profesional. En muchas ocasiones, profesionales de ciertas provincias deben regirse a los códigos éticos de otras. Del análisis realizado se evidencia una falta de organización e interés en los colegios de profesionales del Ecuador en esta rama, para elaborar una normativa general en la que todos se orienten.

\section{Bibliografía}

Colegio de Psicólogos del Perú. (2018). Código de ética y deontología de Perú. (p. 13). p. 13.

Colegios de Psicologos de la Provincvia de Chubut. (2001). Código de ética. 1-17.

Contreras, E. J. C., Medinaceli, A., Diago, O. L. S., \& Villamar, A. A. (2015). Código de Ética para la Investigación, la Investigación-Acción y la Colaboración Etnocientífica en América Latina. Versión Dos. Etnobiología, 13(4), 5-6.

Consejo General de Colegios de Psicologos de España. (2009). Etica Profesional y psicologia.

Dávila, V. A. (2005). Ética y educación para el nuevo siglo. Revista educación, 29(1), 9-14.

Del Perú, C. D. P. (2004). Código de ética profesional. Recuperado de

http://www.colegiodepsicolog osperu.org/w/imagenes/enlac es/archivos/CodigoEticaPeru. pdf. 
Ferrero, A., \& Andrade, E. (2007). Propuestas vigentes para la formación ético-deontológica en Carreras de Psicología en el contexto del Mercosur. El caso argentino. (Spanish). Current Proposals for an Ethic-Deontological Education in Psychology Undergraduate Programs within Mercosur Context. The Argentinean Case. (English), (15), 163178. Retrieved from http://ezproxy.umsl.edu/login? url=http://search.ebscohost.c om/login.aspx?direct=true \&db $=$ afh $\& A N=27873998 \&$ site $=e h$ ost-live \&scope $=$ site

Lindsay, G. (2009). Ética profesional y psicología. Papeles del psicólogo, 30(3), 184-194.

Rodríguez, E., Lolas, F., GarbiNovaes, M. R., Alicia, C., Cardozo, J. I. C., Rodríguez, K., ... \& Valencia-Marroquín, H. E. (2006). Integridad ética en la investigación en Latinoamérica. Journal of the National

Cancer Institute, 98(6), 373-376.

Sociedad Mexicana de Psicología. (2007). Codigo De etica de Psicologos de Mexico. 59.

Valcarce, D. P., Rodríguez, E. R., \& Talavera, M. D. M. L. (2017). Códigos éticos en el ciberperiodismo español y latinoamericano. Naveg@ métrica. Revista electrónica editada por la Asociación Española de Americanistas.
Winkler, M. I., Velázquez, T., Rivera, M., Castillo, T., Rodríguez, A., \& Ayala, N. (2016). Ética y formación en psicología comunitaria: análisis de programas de asignaturas en universidades latinoamericanas. Interameric an Journal of Psychology, 50(1), 23-31. 